\title{
Audiospatial and Visuospatial Working Memory in 6-13 Year Old School Children
}

\author{
Virve Vuontela, ${ }^{1,2}$ Maija-Riikka Steenari, ${ }^{1,2,3}$ Synnöve Carlson, ${ }^{1,2,4}$ Juha Koivisto, ${ }^{1,2,5}$ \\ Mika Fjällberg, ${ }^{3}$ and Eeva T. Aronen ${ }^{2,3}$ \\ ${ }^{1}$ Institute of Biomedicine/Physiology, FIN-00014 University of Helsinki, Helsinki, Finland; ${ }^{2}$ Neuroscience Unit, FIN-00014 University of Helsinki \\ Helsinki Brain Research Center, Helsinki, Finland; ${ }^{3}$ Hospital for Children and Adolescents, Child Psychiatry, FIN-00029 Helsinki University \\ Central Hospital, Helsinki, Finland; ${ }^{4}$ Faculty of Veterinary Medicine, Laboratory Animal Unit, FIN-00014 University of Helsinki, Helsinki, \\ Finland; ${ }^{5}$ Functional Brain Imaging Unit, FIN-00029 Helsinki University Central Hospital, Helsinki Brain Research Center, Helsinki, Finland
}

\begin{abstract}
The neural processes subserving working memory, and brain structures underlying this system, continue to develop during childhood. We investigated the effects of age and gender on audiospatial and visuospatial working memory in a nonclinical sample of school-aged children using n-back tasks. The results showed that auditory and visual working memory performance improves with age, suggesting functional maturation of underlying cognitive processes and brain areas. The gender differences found in the performance of working memory tasks suggest a larger degree of immaturity in boys than girls at the age period of 6-10 yr. The differences observed between the mastering of auditory and visual working memory tasks may indicate that visual working memory reaches functional maturity earlier than the corresponding auditory system.
\end{abstract}

Working memory refers to a cognitive system that allows us to maintain and manipulate information in mind for short periods of time. This system plays a critical role in many forms of complex cognition such as learning, reasoning, problem solving, and language comprehension. Working memory is postulated to be composed of a central executive control system monitoring two independent subsystems, visuospatial sketchpad for spatial processing and phonological loop for nonspatial, mainly verbal information processing (Baddeley 1986, 1992). The functioning of working memory via the central executive system is suggested to be strongly dependent on the frontal lobes (Baddeley 1996). Studies on nonhuman primates (Goldman-Rakic 1987; Fuster 1989; Funahashi and Kubota 1994) and human subjects (Braver et al. 1997; Carlson et al. 1998; Rypma and D'Esposito 1999; Martinkauppi et al 2000) also indicate the importance of the prefrontal cortex in working memory processing.

The neural processes subserving working memory and brain structures underlying this system continue to develop during childhood. The prefrontal cortex is one of the last brain regions to mature, and it has been suggested that developmental changes in this brain area parallel the cognitive development during childhood (Dempster 1992; Casey et al. 2000; Luna et al. 2001). Maturation of the brain is accompanied by faster information processing, and an increase in short-term memory capacity and reasoning ability,

${ }^{5}$ Corresponding author.

E-MAIL eeva.aronen@hus.fi; FAX 358-9-47180688.

Article and publication are at http://www.learnmem.org/cgi/doi/ $10.1101 / \mathrm{lm} .53503$. which all seem to follow a similar time course (Dempster 1981; Hale 1990; Fry and Hale 2000). An age-related improvement has been reported in the performance of a variety of frontal lobe-dependent tasks including working memory, susceptibility to interference, and inhibition of inappropriate responses (Hale et al. 1997; Luciana and Nelson 1998; Luna et al. 2001; Bunge et al. 2002). Working memory in children has also been assessed recently by functional magnetic resonance imaging (fMRI) by use of verbal (Casey et al. 1995) and visuospatial (Thomas et al. 1999; Nelson et al. 2000; Steenari et al. 2001) stimuli. These studies indicate that working memory-related activation in the child brain is of greater magnitude and distributed in a more diffuse manner compared with adult brain, possibly reflecting ongoing maturation and synaptic fine tuning in the child brain (Bourgeois et al. 1994; Casey et al. 2000). However, very little research has been done to elucidate the specific developmental changes occurring in working memory functions at different age levels in boys and girls. Better understanding of the development of working memory functions would help in determining what is normal and pathological at different ages and in developing new ways of learning and teaching.

We have recently investigated visual and auditory working memory in adults with both behavioral (Anourova et al. 1999; Vuontela et al. 1999) and neuroimaging (Carlson et al. 1998; Martinkauppi et al. 2000; Vuontela et al. 2000; Rämä et al. 2001) methods using n-back tasks. This task paradigm allows manipulation of the memory load by changing the instructions while maintaining all other features of the task (number of stimuli, number and type of

LEARNING \& MEMORY 10:74-81 @ 2003 by Cold Spring Harbor Laboratory Press ISSN1072-0502/03 \$5.00

$$
\begin{array}{llllllllllllllll} 
& E & A & R & N & I & N & G & \mathbf{Q} & M & E & M & O & R & Y \\
\text { www.learnmem.org } & & &
\end{array}
$$


response) constant (Braver et al. 1997; Carlson et al. 1998). Having these properties, the n-back task is also especially well suited for studying children both behaviorally and with neuroimaging methods.

Previous research in children has assessed mainly verbal and visuospatial working memory (Casey et al. 1995; Fernández et al. 1998; Luciana and Nelson 1998; Thomas et al. 1999; Nelson et al. 2000). To our knowledge, there are no previous studies on audiospatial working memory in children. The purpose of the present study was to examine the effects of age and gender on the performance of visual and auditory n-back tasks with three different load levels (0-back, 1-back, 2-back) in a nonclinical sample of schoolaged children. The information obtained was intended to provide normative data before studying clinical populations. We also aimed to validate the paradigm before applying it during fMRI in children (Steenari et al. 2001).

\section{RESULTS}

\section{The Effects of Age, Gender, Task, and Load on Working Memory Performance}

\section{Reaction Times}

The performance speed increased with age in all visual tasks. In auditory tasks, the performance speed also increased in 9-10 and 11-13 year olds, but the youngest age group was as fast or faster than 9-10 year olds (Table 1, Figs. 1A and 2A). A significant interaction effect on reaction time was found between age and visual/auditory task $(\mathrm{F}=15.44, P<0.001)$. The boys performed the tasks significantly faster than the girls (Table 1 ; Fig. 2A). In the age groups of 6-8 and 9-10 year olds, the difference in reaction times between the genders was greater than in the age group of 11-13 year olds (interaction effect, $F=3.57$, $P=0.06)$.

All visual tasks were performed significantly faster than the corresponding auditory ones. The reaction times in both auditory and visual tasks became longer as the memory load increased (Table 1, Fig. 1A).

\section{Incorrect Responses}

The performance accuracy increased significantly with age in all visual and auditory tasks (Table 1, Fig. 1A). Girls made fewer errors than boys (Table 1, Fig. 2B). This difference in accuracy between the genders was most evident in the age group of 6-8, weaker in the age group of 9-10, and actually nonexistent in the age group of 11-13 year olds (interaction effect, $\mathrm{F}=4.25, P=0.05$ ). All subjects made fewer errors in the visual than in the corresponding auditory tasks (Table 1, Fig. 1A).

\section{Missed and Multiple Responses}

Increase in age was related to significantly fewer missed and multiple responses in visual and auditory tasks (Table 1).

\begin{tabular}{|c|c|c|c|}
\hline Behavioral measure & $\begin{array}{l}\text { Main } \\
\text { effect }\end{array}$ & $\begin{array}{l}\text { Unstandardized } \\
\text { Regression } \\
\text { Coefficients (B) }\end{array}$ & $P<$ \\
\hline \multirow[t]{4}{*}{$\mathrm{RTs}(\mathrm{ms})$} & Age & -50.68 & 0.001 \\
\hline & Gender & -57.90 & 0.01 \\
\hline & Task & -226.87 & 0.001 \\
\hline & Load & 81.26 & 0.001 \\
\hline \multirow[t]{4}{*}{ Incorrect (\%) } & Age & -3.48 & 0.001 \\
\hline & Gender & 4.31 & 0.001 \\
\hline & Task & -2.74 & 0.05 \\
\hline & Load & -1.11 & n.s. \\
\hline \multirow[t]{4}{*}{ Missed (\%) } & Age & -1.22 & 0.001 \\
\hline & Gender & -1.17 & n.s. \\
\hline & Task & 0.76 & n.s. \\
\hline & Load & 0.28 & n.s. \\
\hline \multirow[t]{4}{*}{ Multiple (\%) } & Age & -1.12 & 0.001 \\
\hline & Gender & 1.55 & 0.005 \\
\hline & Task & -0.31 & n.s. \\
\hline & Load & 0.72 & 0.05 \\
\hline \multirow{4}{*}{$\begin{array}{l}\text { Subjective difficulty } \\
\text { (ratings } 1-5 \text { ) }\end{array}$} & Age & -0.14 & 0.001 \\
\hline & Gender & -6.85 & n.s. \\
\hline & Task & -0.19 & 0.05 \\
\hline & Load & 0.23 & 0.001 \\
\hline
\end{tabular}

(ms) Milliseconds; (\%) percentage; (n.s.) nonsignificant.

This age effect was most evident in the age group of 6-8 year olds (Fig. 1B). Boys made significantly more multiple responses than girls (Table 1, Fig. 2C). This difference between the genders was clear in the age group of 6-8 year olds, but nonexistent in the older age groups (interaction effect, $\mathrm{F}=6.86, P<0.01)$. The number of multiple responses increased with increasing memory load (Table 1, Fig. 1B).

\section{Subjective Evaluation of Working Memory Performance}

The youngest children considered the tasks more difficult than the 9-10 and 11-13-year-old children who did not significantly differ in their evaluations from each other (Table 1, Fig. 3A). Subjectively, all auditory tasks were considered more difficult than the visual tasks. The difficulty of all tasks was considered to increase with increasing memory load.

The distribution of strategies used in the performance of memory tasks is illustrated in Figure 3B. Most subjects (mean $75 \%$ ) reported that they performed all load levels of auditory and visual memory tasks without using any particular strategy.

\section{DISCUSSION}

The present study examined the effects of age and gender on audiospatial and visuospatial working memory in a nonclinical sample of school-aged children. In general, increase in age was related to better accuracy and faster perfor-

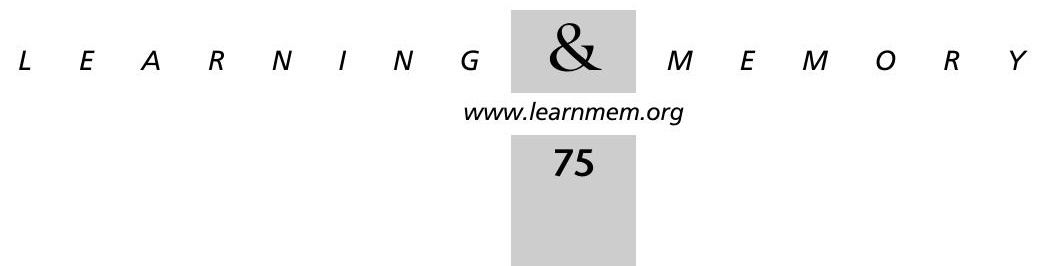


A
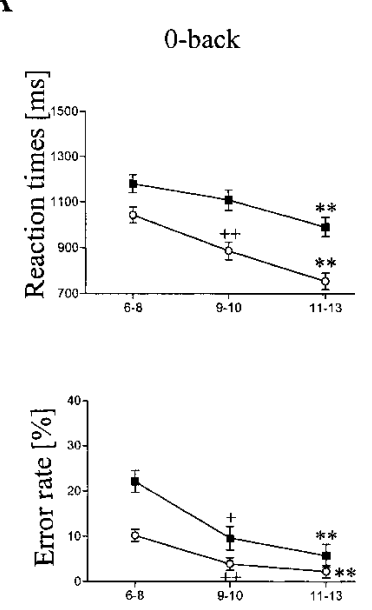

$\mathrm{B}$
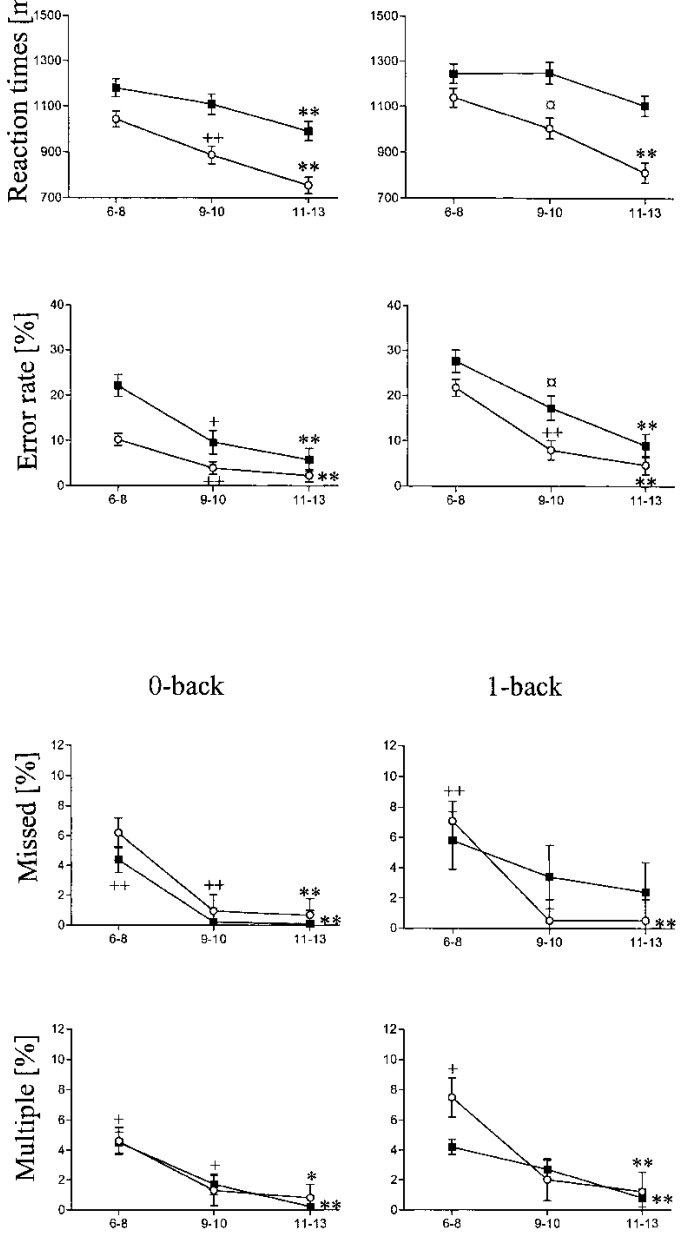

1-back

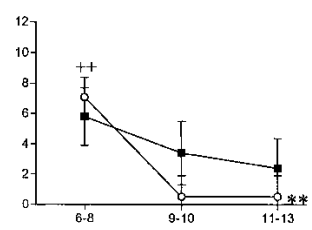

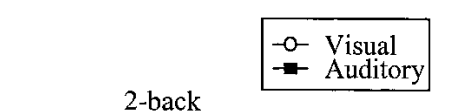
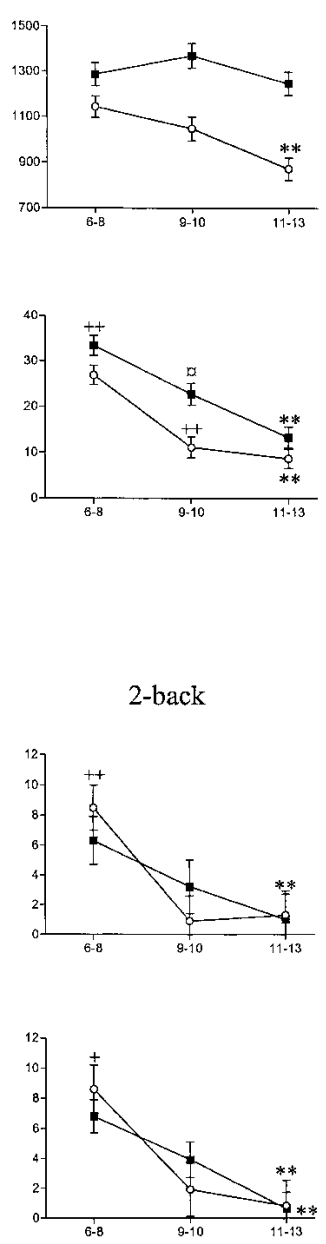

Figure 1 The behavioral performance of auditory and visual 0-back, 1-back, and 2-back tasks in the three age groups of children. $(A)$ The mean reaction times and percentages of incorrect responses. $(B)$ The mean percentages of missed and multiple responses. Vertical lines indicate SEM; (+) the difference is significant between $6-8$ and $9-10$ year olds, $P<0.05 ;(++) P<0.01 ;\left({ }^{*}\right)$ the difference is significant between $6-8$ and $11-13$ year olds, $P<0.05 ;\left(^{* *}\right) P<0.01 ;(\bullet)$ the difference is significant between $9-10$ and $11-13$ year olds, $P<0.05$.

mance in the memory tasks. Boys had shorter reaction times, were less accurate, and made more errors of commission (multiple responses) than girls. These differences between the genders were most evident in the youngest age group (6-8 year olds) and negligible in the oldest age group (11-13 year olds). Visual tasks were performed faster and more accurately than the corresponding auditory ones.

The age-related improvement we found in the performance of working memory tasks is in line with several earlier studies employing a variety of cognitive tasks (Hale et al. 1997; Luciana and Nelson 1998; Kemps et al. 2000). In these studies, younger children performed worse than the older ones, who nevertheless did not reach the adult level of performance. The n-back task paradigm used in the present study has also been used to study nonspatial (Casey et al. 1995) and visuospatial (Thomas et al. 1999; Nelson et al. 2000) working memory in children and adults. In these studies, adults were superior to children in their performance. Similarly, the children in the present study did not quite reach the level of accuracy and speed reported previously in adult subjects (Anourova et al. 1999; Vuontela et al. 1999). This result supports the idea that the physiological development and organization of the prefrontal cortex that continues throughout childhood and adolescence is accompanied by the development of such cognitive abilities as working memory and attention that are attributed to the prefrontal cortex (Casey et al. 2000; Luna et al. 2001).

The 9-10 year olds performed the 2-back auditory tasks more accurately, but slower than the younger children. This result indicates that 9-10 year olds were more capable than 6-8 year olds to manage tasks that placed high demands on executive functions and memory capacity. This finding is in line with the study by Luciana and Nelson (1998) who suggested that 4-7-year-old children express both mnemonic and executive failures, whereas in 8-year-old children, executive functions were found to be at use, but lack functional integrity. On the other hand, the finding that the youngest children performed the 2-back auditory tasks faster but less accurately than the 9-10 year olds, may indicate that the younger children are behaviorally more impulsive than the older children due to a larger degree of immaturity in their cognitive control systems. This is also supported by the greater percentage of multiple responses in this age group. These findings are in line with the notion that cognitive control-the ability to inhibit irrelevant information and inappropriate responses-develops gradually over childhood (Dempster 1992). Several studies have shown that children are more susceptible to interference and less able to withhold inappropriate responses than

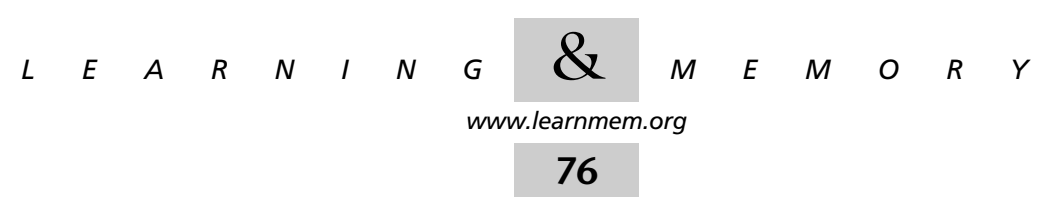


A

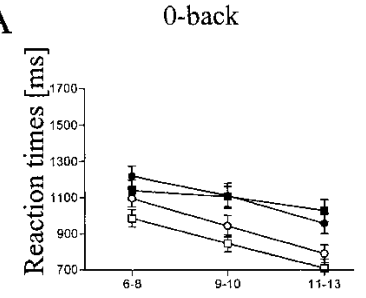

$\mathrm{B}$

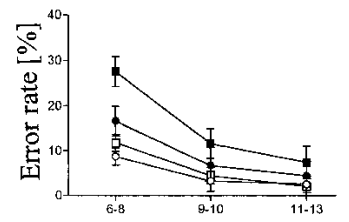

C

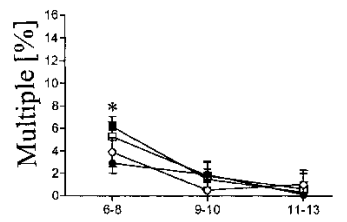

1-back
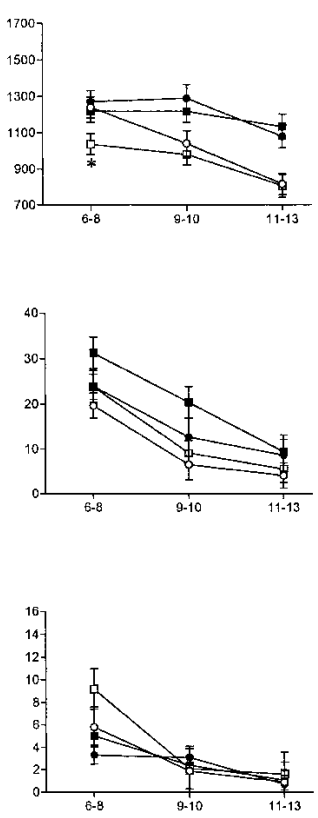
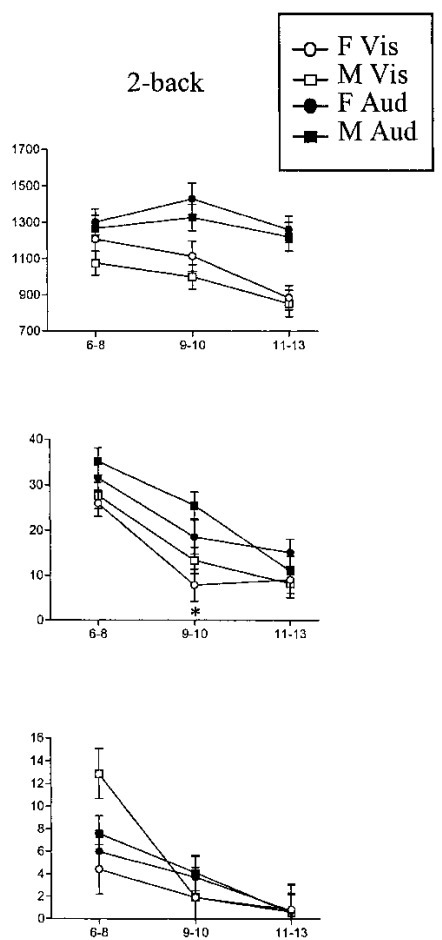

Figure 2 The behavioral performance of auditory and visual 0-back, 1-back, and 2-back tasks in boys and girls in the three age groups of children. $(A)$ The mean reaction times, $(B)$ mean percentages of incorrect responses, and $(C)$ mean percentages of multiple responses. ( $F)$ Female; $(M)$ male; (Vis) visual tasks; (Aud) auditory tasks. Vertical lines indicate SEM. $\left({ }^{*}\right)$ The difference between boys and girls is significant, $P<0.05$.

adults (Casey et al. 1997; Hale et al. 1997; Luna et al. 2001; Bunge et al. 2002). Memory, attention, and inhibition are suggested to be parts of a single construct of a common underlying neural circuitry (Casey et al. 2000). In working memory performance, these processes are not easily separable from each other, as both memory and attention are intertwined and seem to also involve inhibitory processes (Smith and Jonides 1999; Casey et al. 2000).

On the basis of the subjective reports in our study, it is likely that the age-related improvement in working memory task performance was not due to differences in strategy usage. Only $25 \%$ of the children of all age groups reported that they had used some strategy in the memory tasks. Young children $(<8 \mathrm{yr})$ are suggested to rely on visual codes to remember pictorial material, due to difficulties in recoding visual information into a verbal form, whereas older children are able to complement visual coding by phonological coding (Kemps et al. 2000). It is possible, however, that especially the youngest children were not able to describe verbally all the strategies they might have used.

In the present study, boys had shorter reaction times, were less accurate, and made more multiple responses than girls. These gender differences were most prominent in the group of 6-8 year olds. Whereas all children in the youngest age group expressed immature cognitive control in their performance of the tasks, boys in this age group manifested significantly more impulsive behavior than girls. These results suggest that the maturation of executive systems including cognitive control takes longer in boys than girls. This is an interesting finding as impulsive behavior, attentional difficulties, and deficits in working memory function are typical symptoms of Attention Deficit Hyperactivity Disorder (ADHD). The prevalence of ADHD is three- to ninefold in young boys as compared with girls (Jensen et al. 1997). It is possible that in some boys the ADHD-like symptoms reflect the slower maturation of the prefrontal cortex in boys than girls, and not the disorder as such.

Previous reports on gender differences in working memory in children are virtually missing. To our knowledge, the present study is the first to demonstrate an agerelated difference between boys and girls in the performance of working memory tasks. Because the subjects were volunteers from elementary schools and mainly from families of high socioeconomic status, the generalizability of the present results might be somewhat limited. Also, with a larger sample size, the differences between genders may have been more significant.

In the present study, there were differences between the auditory and visual working memory tasks. The visual tasks were performed faster and more accurately and regarded as easier than the corresponding auditory tasks, suggesting that there was a difficulty difference between the tasks. In designing the auditory and visual tasks, we used information from our earlier studies in adults, using spatial n-back tasks with three auditory (Anourova et al. 1999; Martinkauppi et al. 2000) and eight visual locations (Carlson et al. 1998; Vuontela et al. 1999). In the control experiment in the study of Martinkauppi et al. (2000), in which three locations were used in both visual and auditory n-back tasks, the auditory task proved more difficult than the visual one. Because an increase in the number of possible targets has been shown to be related to an increase in the difficulty level (Sternberg 1966; Dobkins and Bosworth 2001), in the present investigation, we used three auditory and eight visual locations as in our earlier studies in adults. Nevertheless, the visual tasks were performed better. However, the auditory and visual stimuli were not in identical locations

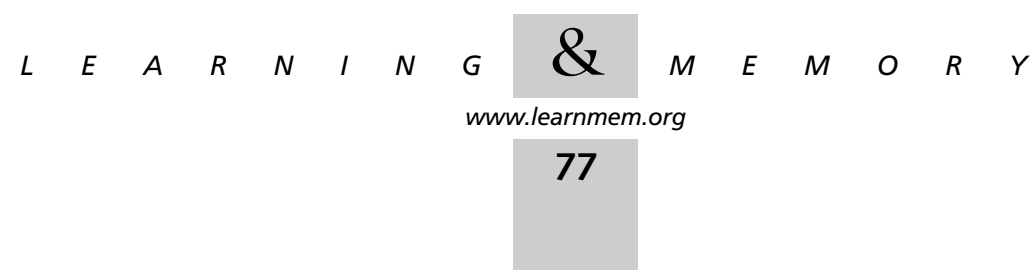


A

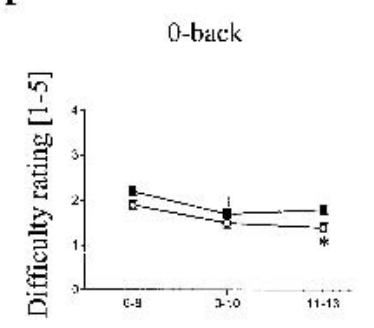

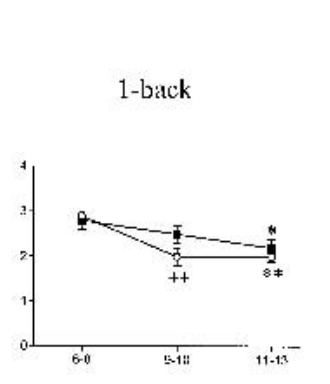
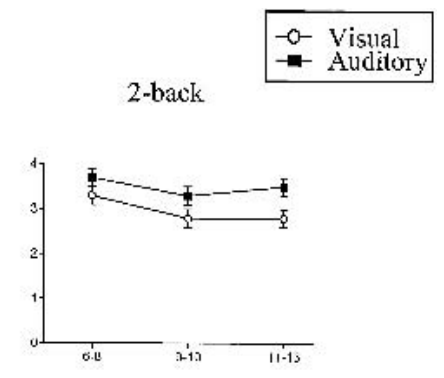

B

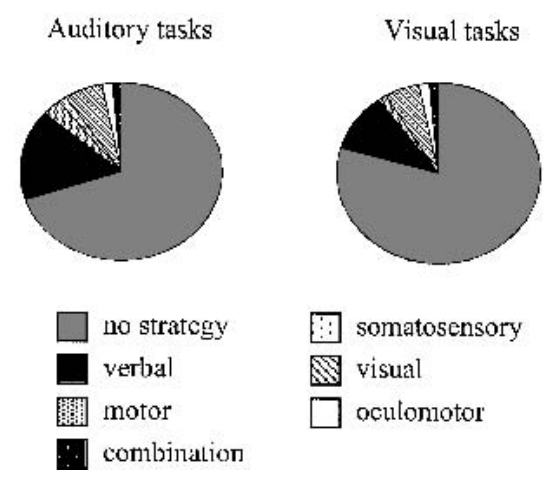

Figure 3 The descriptive measures of working memory performance. (A) Subjective difficulty ratings in the three age groups of children. $(B)$ Illustration of the distribution of reported strategies used in the auditory and visual working memory tasks. Vertical lines indicate SEM. (+) The difference is significant between $6-8$ and $9-10$ year olds, $P<0.05 ;(++) P<0.01 ;\left(^{*}\right)$ the difference is significant between $6-8$ and $11-13$ year olds, $P<0.05 ;(* *) P<0.01$.

and thus not directly comparable. Therefore, and due to the nature of our study design, one should evaluate the difficulty differences between auditory and visual tasks with caution. There is ample evidence concerning visual dominance in spatial perception (King et al. 2000; Kitagawa and Ichihara 2002; Pouget et al. 2002), but there are no reports on possible differences between visuospatial and audiospatial working memory processing. The difference in the performance level was not related to an inability to localize the sound stimuli, because the ability of the subjects to detect all auditory locations was confirmed during a rehearsal session before the experiment. Furthermore, the center location was adjusted individually for each subject. The differences between the auditory and visual task performances may also indicate that visual working memory reaches functional maturity earlier than the corresponding auditory system. Our observation that children aged 11-13 yr performed visual 1-back and 2-back tasks almost at the level reported previously for adults (Vuontela et al. 1999), but the corresponding auditory tasks clearly below the adult level (Anourova et al. 1999), is not necessarily due to the difficulty differences between the tasks. This preliminary finding may be an indication of a more protracted maturation of auditory than visual working memory. Further investigation is required to establish whether such differences exist be- tween the development of visual and auditory working memory processing.

The n-back task paradigm proved to be a suitable tool for studying cognitive processes in normal school-aged children. With this paradigm, it might be possible to increase diagnostic accuracy and treatment specificity in children with clinical disorders. Some subtypes of children with learning disabilities have already been differentiated on the basis of their performance in working memory tasks (Siegel and Ryan 1989).

To conclude, the results of the present study show that auditory and visual working memory performance in school-aged children improves with age, suggesting functional maturation of the underlying cognitive processes and brain structures. The development of the performance of working memory tasks follows a different time course in girls and boys, suggesting a larger degree of immaturity in the male than the female executive systems in children aged 6-10 yr. The differences in mastering auditory and visual working memory tasks may indicate that visual working memory reaches functional maturity earlier than the corresponding auditory system.

\section{MATERIALS AND METHODS}

\section{Subjects}

A total of 66 schoolchildren (mean age $9.9 \mathrm{yr}, \mathrm{SD} \pm 1.9$, female/ male ratio 0.9$)$ participated in the study: twenty-four 6-8 year olds (12 females, 12 males), twenty 9 -10 year olds ( 8 females, 12 males) and twenty-two 11-13 year olds (12 females, 10 males). The children were recruited by advertising from three schools in Helsinki, Finland. All children were Caucasian and of Finnish nationality. A written permission was obtained from the parents and a verbal assent from the child. Of the parents, $64 \%$ were classified as belonging to the socioeconomic class I, $24 \%$ to socioeconomic class II, $8 \%$ to socioeconomic class III, and $4 \%$ to socioeconomic class IV (Helsinki city socioeconomic classification, I representing the highest and IV the lowest). The children were screened for psychiatric symptoms with Child Behavior Checklist (CBCL, Achenbach 1991, mean 48.27, SD 8.98, range 26-65), Children's Depression Inventory (CDI, Kovacs 1985, mean 3.89, SD 3.68, range 0-19), and Teacher's Report Form (TRF, Achenbach 1991, mean 46.15, SD 7.94, range 31-63). The clinical borderline was exceeded in CBCL and CDI by three and two children, respectively, but these children

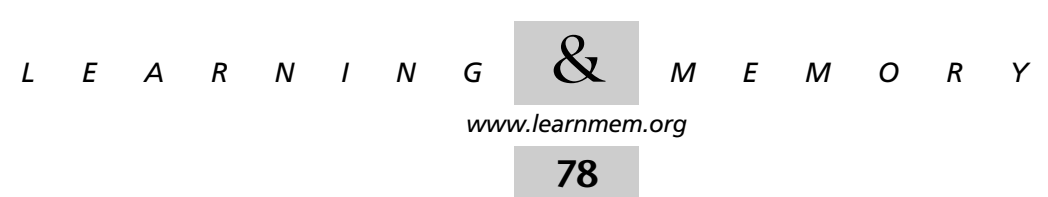


A

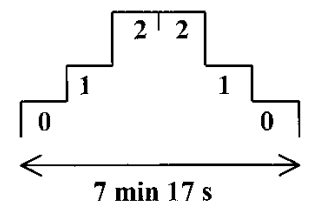

B

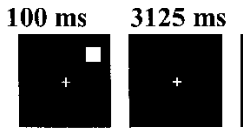

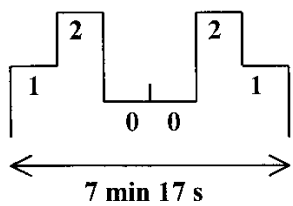

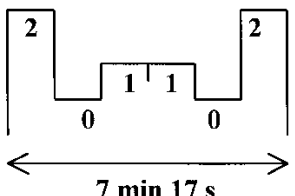

$7 \min 17 s$
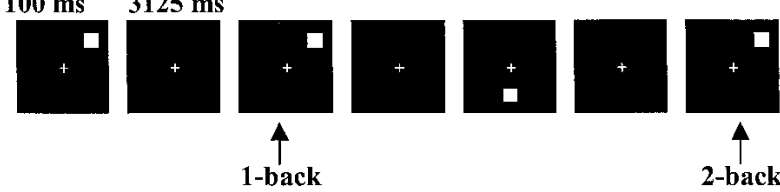

2-back
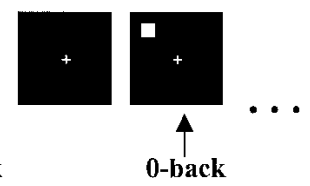

$\mathbf{C}$
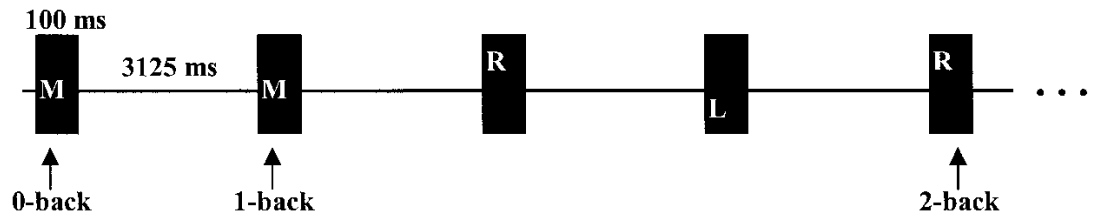

Figure 4 The experimental design. (A) The temporal order of the 0-back, 1-back, and 2-back tasks in the three consecutive blocks of each session. $(7 \mathrm{~min}, 17 \mathrm{sec})$ The duration of each individual block. $(B)$ Illustration of the visuospatial working memory tasks. The match trials for 0-back, 1-back, and 2-back tasks are marked with vertical arrows. (100 msec) The duration of each stimulus; (3125 msec) the delay period between the stimuli. (C) Illustration of the audiospatial working memory tasks. (L) Left; (M) middle; (R) right.

were not excluded. One child was excluded because of dysphasia and another because of lack of cooperation. Prior experience with computers was reported by $75 \%$ of the $6-8$ year olds, $85 \%$ of the 9-10 year olds, and $100 \%$ of the 11-13 year olds. The study protocol was approved by the Ethics Committee for Pediatrics, Adolescent Medicine, and Psychiatry at the Helsinki University Central Hospital.

\section{Test Stimuli}

The visual stimuli (duration $100 \mathrm{msec}$, interstimulus interval, ISI, $3225 \mathrm{msec})$ were light gray $(60 \%$ gray $)$ squares $\left(2.2 \times 2.2^{\circ}\right)$ presented randomly in one of eight locations around a fixation cross at eccentricities $4.2-6.0^{\circ}$. The mean luminance of the gray squares was $20 \mathrm{~cd} / \mathrm{m} 2$ and that of the background $4 \mathrm{~cd} / \mathrm{m} 2$, measured with a MAVOLUX 5032C/B Digital Luxmeter with a luminance attachment. The auditory stimuli (duration $100 \mathrm{msec}$ including $10-\mathrm{msec}$ rise and fall time, ISI 3225) were tones of $2250 \mathrm{~Hz}$ presented binaurally through earphones in one of three locations, left, right, and middle. The left and right locations were simulated by an interaural intensity difference of $17 \mathrm{~dB}(\sim 58$ and $75 \mathrm{~dB}$ SPL for each ear, measured with a Precision Sound Level Meter Type 2203, Bruel and Kjaer, Naerum, Denmark, Anourova et al. 1999), and the middle location by presenting the tones at an equal intensity ( $70 \mathrm{~dB}$ SPL). The presentation of the stimuli was controlled by a computer program (Presentation 0.31, Neurobehavioral Systems, Inc.), which also collected behavioral data (correct and incorrect responses, misses, multiple responses, and reaction times).

\section{N-Back Tasks}

The 0-back, 1-back, and 2-back visuospatial and audiospatial tasks were used (Fig. 4). In the visual 0-back task, the subject pressed the left button of the mouse with the right index finger if the stimulus tions of 2-back tasks, presented in a counterbalanced order. Thus, each subject was presented a total of 360 trials of visual and 360 trials of auditory tasks (120 trials of 0-back, 1-back, and 2-back tasks in both task types), altogether 720 trials including $30 \%$ match trials. There was a $10-\mathrm{sec}$ pause between the conditions in a block, and the subjects were allowed to have a short break between the blocks.

\section{General Procedure}

The memory tasks were presented with a portable computer. The subjects were tested individually in a quiet room at the school during a school day or in the Hospital for Children and Adolescents. To avoid possible problems of fatigue, the experiment was conducted in two separate sessions on different days. Approximately half of the subjects performed the visual tasks in the first session and the auditory tasks in the second; for the other half, the order was reversed. At the beginning of each session, the memory task was explained, and children were allowed to practice until they understood the nature of the task; this was controlled by checking the log file of the performance. On average, the subjects practiced 20 trials of each condition before starting the experiment. The subjects faced the computer screen with the chin on a chin rest 57 $\mathrm{cm}$ from the center of the screen. After the memory tasks, they were asked to evaluate the difficulty level of the tasks on a fivepoint scale [(1) very easy, (2) easy, (3) intermediate, (4) difficult, and (5) very difficult] and to describe the strategies they used.

\section{Data Analysis}

The percentage of incorrect responses in each condition was counted for the 120 trials in the 0-back, and for 114 trials in the 1-back, and 108 trials in the 2-back tasks because the responses to the first stimulus in the 1-back and to the first two stimuli in the

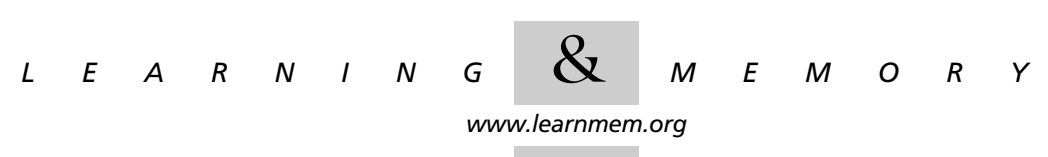


2-back tasks required no working memory processing. Analysis of variance for repeated measures (ANOVA) was applied to the behavioral data (percentages of incorrect, missed and multiple responses, reaction times, and subjective difficulty level). The significance level was set at $P<0.05$. If the ANOVA gave a significant main effect, post hoc analyses were performed with Tukey HSD and paired $t$-tests. Task (visual vs. auditory) $\times$ load (0-back, 1-back, 2-back) served as within, and age $\times$ gender served as between factors in the design. There was, however, a high correlation among the target variables that made the repeated ANOVA extremely sensitive and the rejection of the null hypothesis rather difficult. Furthermore, the analysis did not allow the investigation of the interaction between some of the within-between factors. For these reasons, the analysis was carried out by stacking the repeated measures and indicating their attributes with dummy variables (Kerlinger 1976). This increased the number of cases to an artificial $6^{*} 66=396$. When comparing the results, we found the latter analysis more realistic. The third-order interactions that were actually due to the too-powerful nature of the repeated ANOVA were excluded when using the stacked ANOVA. The nature of interaction was confirmed by using residual scores where the main effects were partialled out. The effect of age was analyzed by treating it as a continuous variable and within three subgroups $(6-8,9-10$, and 11-13 year olds).

\section{ACKNOWLEDGMENTS}

We thank the children who volunteered to participate in this study. We appreciate the supportive attitude and cooperation of the personnel in the Munkkivuori, Taivallahti, and Kaisaniemi schools in Helsinki. Erkki Komulainen is denoted for invaluable statistical guidance, and Ilkka Linnankoski for his help in revising the language. This study was supported by grants from the Signe and Ane Gyllenberg Foundation, the Yrjö Jahnsson Foundation, the Finnish Cultural Foundation, Helsinki University Central Hospital, the Academy of Finland, and the Finnish Graduate School of Neuroscience.

The publication costs of this article were defrayed in part by payment of page charges. This article must therefore be hereby marked "advertisement" in accordance with 18 USC section 1734 solely to indicate this fact.

\section{REFERENCES}

Achenbach, T.M. 1991. Integrative guide for the 1991 CBCL/4-18, YSR and TRF profiles. University of Vermont, Department of Psychiatry, Burlington, VT.

Anourova, I., Rämä, P., Alho, K., Koivusalo, S., Kahnari, J., and Carlson, S. 1999. Selective interference reveals dissociation between auditory memory for location and pitch. NeuroReport 10: 3543-3547.

Baddeley, A.D. 1986. Working memory. Oxford psychology series No. 11. Clarendon Press, Oxford, UK.

. 1992. Working memory. Science 255: 556-559.

. 1996. The fractionation of working memory. Proc. Natl. Acad. Sci. 93: 13468-13472.

Bourgeois J.P., Goldman-Rakic, P.S., and Rakic, P. 1994. Synaptogenesis in the prefrontal cortex of rhesus monkeys. Cerebral Cortex 4: 78-96.

Braver, T.S., Cohen, J.D., Nystrom, L.E., Jonides, J., Smith, E.E., and Noll, D.C. 1997. A parametric study of prefrontal cortex involvement in human working memory. Neurolmage 5: 49-62.

Bunge, S.A., Dudukovic, N.M., Thomason, M.E., Vaidya, C.J., and Gabrieli, J.D. 2002. Immature frontal lobe contributions to cognitive control in children: Evidence from fMRI. Neuron 33: 301-311.

Carlson, S., Martinkauppi, S., Rämä, P., Salli, E., Korvenoja, A., and Aronen, H.J. 1998. Distribution of cortical activation during visuospatial n-back tasks as revealed by functional magnetic resonance imaging. Cerebral Cortex 8: 743-752.

Casey, B.J., Cohen, J.D., Jezzard, P., Turner, R., Noll, D.C., Trainor, R.J., Giedd, J., Kaysen, D., Hertz-Pannier, L., and Rapoport, J.L. 1995. Activation of prefrontal cortex in children during a nonspatial working memory task with functional MRI. NeuroImage 2: 221-229.

Casey, B.J., Trainor, R.J., Orendi, J.L., Schubert, A.B., Nystrom, L.E., Giedd, J.N., Castellanos, F.X., Haxby, J.V., Noll, D.C., Cohen, J.D., et al. 1997. A developmental functional MRI study of prefrontal activation during performance of a go-no-go task. J. Cog. Neurosci. 9: 835-847.

Casey, B.J., Giedd, J.N., and Thomas, K.M. 2000. Structural and functional brain development and its relation to cognitive development. Biol. Psychol. 54: 241-257.

Dempster, F.N. 1981. Memory span: Sources of individual and developmental differences. Psychol. Bull. 89: 63-100.

- 1992. The rise and fall of the inhibitory mechanism: Toward a unified theory of cognitive development and aging. Dev. Rev. 12: $45-75$.

Dobkins, K.R. and Bosworth, R.G. 2001. Effects of set-size and selective spatial attention on motion processing. Vision Res. 41: 1501-1517.

Fernández, T., Harmony, T., Silva, J., Galán, L., Diaz-Comas, L., Bosch, J., Rodriguez, M., Fernández-Bouzas, A., Yáñez, G., Otero, G., et al. 1998 Relationship of specific EEG frequencies at specific brain areas with performance. NeuroReport 9: 3681-3687.

Fry, A.F. and Hale, S. 2000. Relationships among processing speed, working memory, and fluid intelligence in children. Biol. Psychol. 54: $1-34$.

Funahashi, S. and Kubota, K. 1994. Working memory and prefrontal cortex. Neurosci. Res. 21: 1-11.

Fuster, J.M. 1989. The prefrontal cortex. Raven Press, New York.

Goldman-Rakic, P.S. 1987. Circuitry of primate prefrontal cortex and regulation of behavior by representational memory. In Handbook of physiology, (eds. F. Plum and V.B. Mountcastle), Vol. 5, pp. 373-417. American Physiological Society, Bethesda, MD.

Hale, S. 1990. A global developmental trend in cognitive processing speed. Child Dev. 61: 653-663.

Hale, S., Bronik, M.D., and Fry, A.F. 1997. Verbal and spatial working memory in school-age children: Developmental differences in susceptibility to interference. Dev. Psychol. 33: 364-371.

Jensen, P.S., Martin, D., and Cantwell, D.P. 1997. Comorbidity in ADHD; implication for research, practice, and DSMV. J. Amer. Acad. Child and Adolescent Psych. 36: 1065-1079.

Kemps, E., De Rammelaere, S., and Desmet, T. 2000. The development of working memory: Exploring the complementarity of two models. $J$. Exper. Child Psychol. 77: 89-109.

Kerlinger, F.N. 1976. Foundations of behavioral research. 2nd Ed., Chapter 36, pp. 632-658. Holt, Rinehart and Winston, London, UK.

King, A.J., Parsons, C.H., and Moore, D.R. 2000. Plasticity in the neural coding of auditory space in the mammalian brain. Proc. Natl. Acad. Sci. 97: 11821-11828.

Kitagawa, N. and Ichihara, S. 2002. Hearing visual motion in depth Nature 416: 172-174.

Kovacs, M. 1985. The children's depression inventory (CDI). Psychopharmacol. Bull. 21: 995-998.

Luciana, M. and Nelson, C.A. 1998. The functional emergence of prefrontally-guided working memory systems in four- to eight-year old children. Neuropsychologia 36: 273-293.

Luna, B., Thulborn, K.R., Munoz, D.P., Merriam, E.P., Garver, K.E., Minshew, N.J., Keshavan, M.S., Genovese, C.R., Eddy, W.F., and Sweeney, J.A. 2001. Maturation of widely distributed brain function subserves cognitive development. NeuroImage 13: 786-793.

Martinkauppi, S., Rämä, P., Aronen, H.J., Korvenoja, A., and Carlson, S. 2000. Working memory of auditory localization. Cerebral Cortex 10: 889-898.

Nelson, C.A., Monk, C.S., Lin, J., Carver, L.J., Thomas, K.M., and Truwit, C.L. 2000. Functional neuroanatomy of spatial working memory in children. Dev. Psychol. 36: 109-116.

Pouget, A., Ducom, J-C., Torri, J., and Bavelier, D. 2002. Multisensory

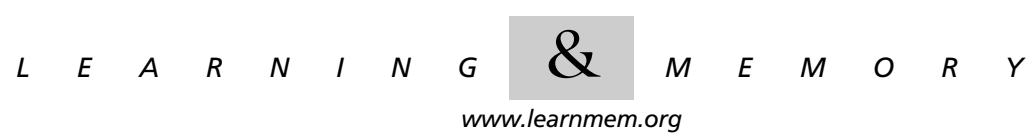


spatial representations in eye-centered coordinates for reaching. Cognition 83: B1-B11.

Rämä, P., Martinkauppi, S., Linnankoski, I., Koivisto, J., Aronen, H.J., and Carlson, S. 2001. Working memory of identification of emotional vocal expressions: An fMRI study. NeuroImage 13: 1090-1101.

Rypma, B. and D'Esposito, M. 1999. The roles of prefrontal brain regions in components of working memory: Effects of memory load and individual differences. Proc. Natl. Acad. Sci. 96: 6558-6563.

Siegel, L.S. and Ryan, E.B. 1989. The development of working memory in normally achieving and subtypes of learning disabled children. Child Dev. 60: 973-980.

Smith, E.E. and Jonides, J. 1999. Storage and executive processes in the frontal lobes. Science 283: 1657-1661.

Steenari, M-R., Vuontela, V., Aronen, E., Koivisto, J., Martinkauppi, S., and Carlson, S. 2001. Visuospatial and color working memory in children as revealed by fMRI. Soc. Neurosci. Abstr. Program number 311.2.
Sternberg, S. 1966. High-speed scanning in human memory. Science 153: 652-654.

Thomas, K.M., King, S.W., Franzen, P.L., Welsh, T.F., Berkowitz, A.L., Noll, D.C., Birmaher, V., and Casey, B.J. 1999. A developmental functional MRI study of spatial working memory. NeuroImage 10: 327-338.

Vuontela, V., Rämä, P., Raninen, A., Aronen, H.J., and Carlson, S. 1999. Selective interference reveals dissociation between memory for location and color. NeuroReport 10: 2235-2240.

Vuontela, V., Martinkauppi, S., Rämä, P., Koivisto, J., Aronen, H.J., and Carlson, S. 2000. Evidence of dissociation between mnemonic processing of visuospatial and color information as revealed by fMRI. Soc. Neurosci. Abstr. 26 Part 1: 974.

Received July 15, 2002; accepted in revised form October 29, 2002.

$\begin{array}{lllllllllllllll} & E & A & R & N & I & N & G & \& & M & E & M & O & R & Y \\ \text { www.learnmem.org } & & & \end{array}$ 


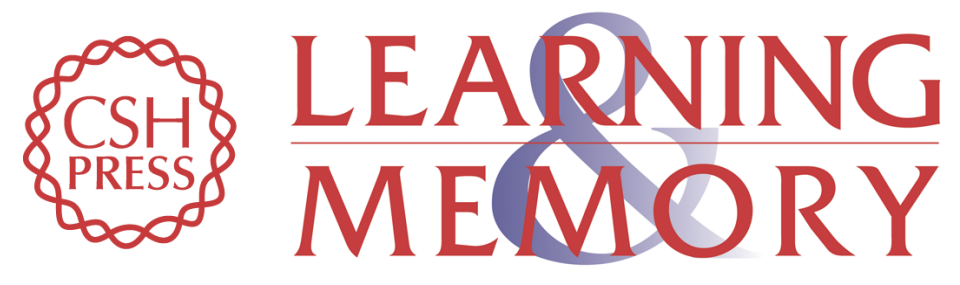

\section{Audiospatial and Visuospatial Working Memory in 6-13 Year Old School Children}

Virve Vuontela, Maija-Riikka Steenari, Synnöve Carlson, et al.

Learn. Mem. 2003, 10:

Access the most recent version at doi:10.1101/lm.53503

References This article cites 34 articles, 6 of which can be accessed free at: http://learnmem.cshlp.org/content/10/1/74.full.htmI\#ref-list-1

License

Email Alerting Receive free email alerts when new articles cite this article - sign up in the box at the Service top right corner of the article or click here. 